\title{
APOIO COLETIVO ÀS MULHERES VÍTIMAS DE VIOLÊNCIA: UM RELATO DE EXPERIÊNCIA
}

\begin{abstract}
Thamires da Silva Sampaio Medrado1, ORCID ID 0000-0003-3260-4936; Maíra Espíndola Torres', ORCID ID 0000-0002-2664-1346; Rafael Cabral de Carli1, ORCID ID 0000-0003-2581-1611; Déborah Emmily de Carvalho', ORCID ID 0000-0002-8068-3598; Lourdes Maria Simões Nunes da Silva², ORCID ID 0000-0001-7784-9799; Ana Maria Medeiros de Ataides $^{3}$, ORCID ID 0000-0002-2896-4421
\end{abstract}

\section{FILIAÇÃO}

(1) Universidade de Pernambuco, campus Santo Amaro, Faculdade de Ciências Médicas, Estudante de Medicina.

(2) Universidade de Pernambuco, campus Serra Talhada.

(3) Universidade de Pernambuco, campus Santo Amaro, Instituto de Ciências Biológicas, Professora Assistente do Instituto de Ciências Biológicas da UPE.

\section{AUTOR CORRESPONDENTE}

Thamires da Silva Sampaio Medrado; thamiressampaio24@gmail.com; Avenida Armindo Moura, 341. Jaboatão dos Guararapes. Piedade; Universidade de Pernambuco, campus Santo Amaro, Faculdade de Ciências Médicas, Estudante de Medicina.

MENSAGENS-CHAVE
- O que já é conhecido sobre o tema? A violência contra a mulher advém de raízes históricas e socioculturais,
intensificadas diante da Pandemia de Covid-19.
- Quais são as novas descobertas? Abordagem interprofissional da temática é um meio de conscientizar, incentivar
o debate, e instigar mudanças de hábitos.
- Em que implicam essas novas descobertas? Eventos online cumprem o papel de transformação social e
possuem maior espectro de atuação do que os presenciais.
- Quais as consequências dos achados? Incentivar e inspirar a realização de eventos semelhantes, a fim de
combater a realidade vigente.

\section{RESUMO}

INTRODUÇÃO: Historicamente, a violência contra a mulher sempre existiu, mas pouco era discutida na sociedade. Com a criação de políticas públicas, como a Lei Maria da Penha, e a valorização do feminismo, pôs-se em pauta a necessidade em se discutir cada vez mais o empoderamento e a liberdade da mulher no contexto familiar. Assim, o objetivo deste relato é descrever as experiências ocorridas durante o evento, além de estimular que eventos semelhantes ocorram. RELATO DE EXPERIÊNCIA. Este relato foi baseado nas experiências ocorridas, durante a Pandemia de Covid-19, nas mesas redondas online dos dias 26, 27 e 30 de novembro, através da plataforma Youtube, durante a atividade Uma Maria Vai Com As Outras, na qual participaram 190 indivíduos que realizaram a inscrição na plataforma Even3. DISCUSSÃO. Através dos comentários no chat do Youtube, pode-se inferir não só o conhecimento proporcionado nas mesas redondas, mas também quão pouco se sabe quanto à postura dos profissionais de saúde diante das vítimas da violência contra a mulher. Foi um momento de oportunidade de troca de conhecimento, a partir dos relatos dos participantes que conviviam com a violência doméstica ou foram vítimas, relatando ter suas dúvidas esclarecidas sobre canais de denúncia e ser incentivados quanto à prestação de queixas, como também ao acompanhamento psicológico. CONCLUSÃo. Apesar das limitações, a atividade orientou os participantes quanto aos aspectos psicológicos e jurídicos envolvidos na violência contra as mulheres. Ademais, a modalidade remota possibilitou atingir um público significativo e proveniente de diversas regiões do país, cenário que seria dificultado na modalidade presencial. Portanto, a conscientização e valorização do acompanhamento psicológico para as vítimas da violência são medidas importantes no combate a esta realidade alarmante. 
PALAVRAS-CHAVE: Violência de Gênero; Assistência à Saúde Mental; Saúde da Mulher.

\begin{abstract}
INTRODUCTION: Historically, violence against women has always existed, but has been little discussed in society. With the creation of public policies, like the Maria da Penha law, and feminism's valorization, the need to speak more about female's empowerment and freedom in the familiar context came up for discussion. Therefore, the purpose of this report is to describe the experiences that occurred during the event, in addition to stimulating the occurrence of similar events. EXPERIENCE REPORT: This report was based on experiences ocurred, during the COVID-19 pandemic, at online roundtables at November 26, 27 e 30, through the platform YouTube, during the activity "Uma Maria Vai Com As Outras", in which 190 individuals subscribed through Even3. DISCUSSION: Through comments in the Youtube chat it is possible to infer not only the knowledge provided at the round tables, but also how little is known about the attitude of health professionals towards the victims of violence against women. It was a moment of opportunity for knowledge exchange, based on the reports of the participants who lived along with domestic violence or were victims of it. The participants told that their doubts were clarified about denunciation channels and were encouraged to denounce, as well as to look for psychological treatment. CONCLUSION: Despite the limitations, the activity guided the participants on the psychological and legal aspects involved in violence against women. In addition, the remote learning format favored a greater reach to students and professionals from different areas of knowledge and regions of the country. This scenario would be harder on-campus. Therefore, awareness and appreciation of psychological attendance for victims of violence are important measures in combating this alarming reality.
\end{abstract}

\title{
KEYWORDS: Gender-Based Violence; Mental Health Assistance; Women's Health.
}

\section{INTRODUÇÃO}

No Brasil, a violência contra a mulher é uma realidade latente, uma vez que coaduna graves consequências físicas e psicológicas para as vítimas, mesmo na vigência de algumas legislações. A Lei Maria da Penha (2006) e a Lei do Feminicídio (2015) visam coibir a violência doméstica e familiar, empregando penas mais severas para o agressor. Entretanto, a falta de efetiva aplicação das medidas previstas gera uma descredibilidade dos mecanismos de proteção feminina ${ }^{1}$. Nesse sentido, é um fenômeno social complexo, já que possui distribuição diferente de acordo com a faixa etária, nível de escolaridade, condição socioeconômica e cor da pele. Segundo o Instituto de Pesquisa Econômica Aplicada (IPEA), há maior prevalência entre jovens de 16 a 24 anos, com pouca escolaridade, nas classes sociais mais desfavorecidas e com mulheres negras ${ }^{2}$. Tal cenário advém de muitos fatores, dentre os quais o nível de instrução e o medo de denunciar são determinantes. O assédio sexual é tão banalizado que as vítimas costumam não reconhecer a agressão ou temem ser descredibilizadas ao denunciá-lo. Ademais, soma-se o sentimento de culpa e o medo de perder o espaço no trabalho, fatores que contribuem para a manutenção da agressão ${ }^{3}$. Na atual pandemia da Covid-19, essas perspectivas foram mais intensificadas ${ }^{4}$ em virtude do prolongamento do contato com o agressor, da dependência financeira e emocional, do medo de adquirir o vírus na delegacia ou no processo de amparo legal. Esses fatos ocasionaram a queda do número de denúncias, conforme dados do Fórum Brasileiro de Segurança Pública ocorrido no ano de $2020^{5}$.

Sendo assim, a violência contra a mulher é um tema extremamente pertinente para a formação acadêmica dos estudantes de medicina, devido à grande responsabilidade dos médicos frente ao atendimento de mulheres vítimas de agressão física, moral ou psicológica. Dessa forma, o projeto "Uma Maria Vai Com As Outras: Apoio coletivo às mulheres vítimas de violência" foi pensado em dar lugar de fala às mulheres que foram vítimas de violência e de auxiliar na formação de profissionais de saúde, informando e instruindo sobre formas de lidar com essas situações. Assim, o projeto abriu espaço para debates, compartilhamento de informações e experiências, e estímulo à busca por mudanças frente ao cenário de violência atual.

O objetivo deste relato é descrever as experiências vivenciadas durante as mesas redondas oferecidas no evento online "Uma Maria Vai Com As Outras: Apoio coletivo às mulheres vítimas de violência", bem como incentivar a realização de outros eventos relacionados à violência contra a mulher.

\section{RELATO}

A atividade foi idealizada durante as reuniões iniciais, em que, a coordenação, composta por oito estudantes de medicina, decidiu que a atividade seria organizada por meio de um evento online. A abordagem interprofissional ocorreu nos dias 26, 27 e 30 de novembro de 2020, das 19h às 21h, através da plataforma do Youtube e no formato de mesa redonda, tendo como público-alvo a sociedade civil.

Um grupo promoveu a divulgação do evento cujas artes foram elaboradas em uma temática que remetesse ao apoio coletivo, uma vez que a problemática é referente a todos os atores sociais, o que também influenciou a escolha do léxico integrativo e sem jargões acadêmicos. Diante disso, escolheuse "Uma Maria Vai Com As Outras: apoio coletivo às mulheres vítimas de violência". A posteriori, decidiu-se publicar as postagens com uma semana de antecedência do evento nas redes sociais WhatsApp, Telegram e Instagram contendo o link que direcionaria para a plataforma Even3, na qual 190 indivíduos fizeram a inscrição. Além disso, também foi enviado um formulário via e-mail contendo um espaço para que os participantes enviassem sugestões e suas principais dúvidas da temática conforme a área das palestrantes, permitindo, assim, a construção colaborativa e integrativa das mesas 
redondas.

Com o intuito de promover uma visão holística da temática, a realização da atividade contou com a participação de uma equipe multiprofissional cuja escolha foi mediada pelas principais áreas envolvidas na violência contra a mulher, buscando a escolha de profissionais experientes e de impacto no estado conforme os objetivos almejados na promoção do evento. O primeiro dia da atividade (26/11/2020), contou com a participação de uma assistente social do planejamento reprodutivo com atuação em Direitos Sexuais e Reprodutivos e uma ativista feminista também advogada e vítima da violência contra a mulher, tendo como tema a "identificação de sinais de abuso e comportamentos tóxicos". O segundo dia (27/11/2020), por sua vez, consistiu na discussão sobre "como um profissional de saúde deve agir perante uma situação de violência doméstica suspeita ou confirmada", sendo intermediada por uma psicóloga clínica e institucional com atuação na Secretaria Executiva de Direitos Humanos e uma psiquiatra com pós-graduação em intervenção psicanalítica. O terceiro dia de atividade (30/11/2020) foi intermediado por uma professora de Direito Penal, uma advogada do centro de apoio a vítimas da violência contra a mulher e uma psicóloga, as quais discutiram sobre "os aspectos jurídicos do atendimento às vítimas de violência contra a mulher". (Figura 1)

É importante salientar, por fim, as limitações que surgiram ao longo do desenvolvimento da atividade. Houve dificuldade inerente ao formato remoto de realização de atividades devido à discrepância entre os números de inscritos e a quantidade de visualizações ao vivo. Além disso, também ocorreu um problema quanto ao horário, pois alguns participantes confundiram devido aos fusos horários diferentes, ressaltando a importância de esclarecê-lo com antecedência nas artes de divulgação. Apesar desses contrapontos, acredita-se que mais atividades feitas de forma online são necessárias, considerando seu amplo alcance de público em relação a eventos presenciais, sem comprometer o aprendizado objetivado.

Figura 1. Programação do Evento

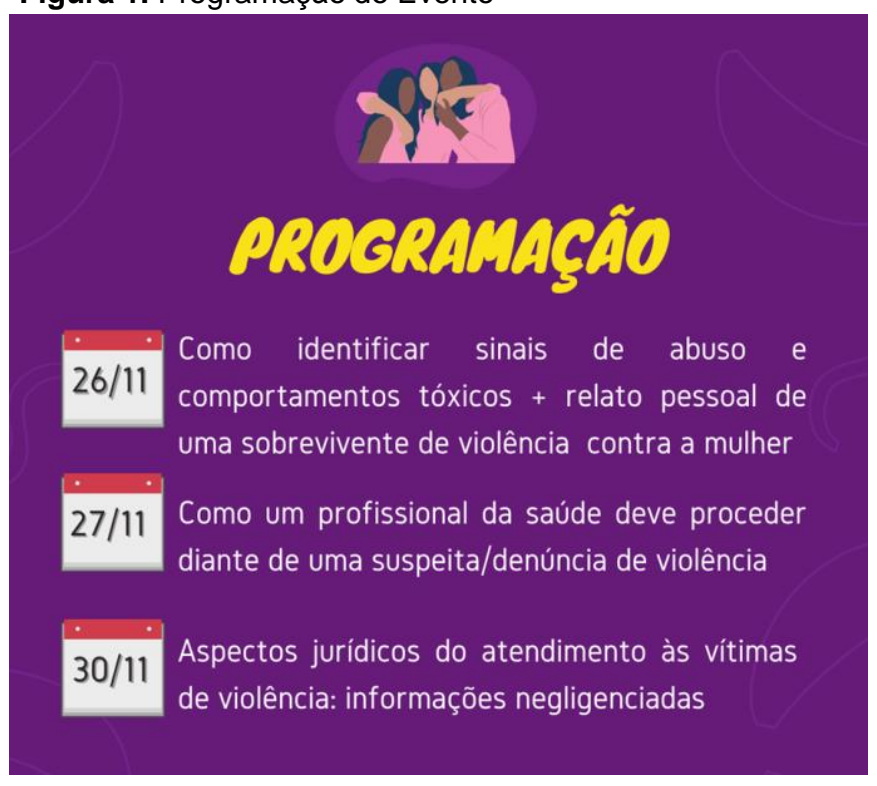

Autoria própria

\section{DISCUSSÃO}

A atividade "Uma Maria vai com as outras" objetivou suscitar o debate e a reflexão acerca do tema da violência contra a mulher, tendo em vista o aumento na média diária de denúncias registradas desde o início da pandemia ${ }^{6}$, efeito de uma maior convivência da vítima com seu agressor. Para tanto, buscou-se aproximar a discussão acadêmica da comunidade, além de afirmar a importância da ampla exposição do tema para a sociedade.

A fim de garantir que as mulheres estejam preparadas para resguardar seus direitos, é fundamental que sejam capacitadas a discernir quais são os sinais de violência e abuso, diferenciando-os de acidentes ou atos não intencionais. Ademais, o acesso à informação de esclarecimento a respeito dos aspectos jurídicos e dos canais de denúncia disponíveis torna as vítimas menos vulneráveis e mais confiantes para se manifestarem ${ }^{7}$.

Para tanto, profissionais da área do direito e mulheres que já passaram pelo mesmo processo foram as palestrantes convidadas na atividade para compartilharem seus conhecimentos na área e serem instrumentos de promoção da autonomia para o público feminino, de modo geral. Sendo assim, foi possível promover a abordagem dos conhecimentos necessários para a conscientização dos participantes acerca da importância da denúncia em casos de violência doméstica, seja pela vítima ou por outros indivíduos que presenciaram o crime. Além disso, as palestrantes destacaram que a queixa da violência às autoridades competentes não deve ser suprimida por medo ou intimidação de qualquer natureza, garantindo, assim, que a vítima tenha seu direito à justiça resguardado pela investigação rápida e imparcial dos fatos alegados.

Em contexto de reclusão pela pandemia, a constatação supracitada de que as mulheres passaram a ficar mais tempo com seu agressor levou à escolha de profissionais da assistência social e da psicologia para compor a equipe de palestrantes. Sob a perspectiva dessas áreas, foi possível tratar com mais detalhes sobre todo o processo pessoal de identificação da ocorrência da violência até a decisão de levar a denúncia adiante, bem como elucidar com mais detalhes como tem sido a influência do isolamento social na ocorrência de agressões em âmbito doméstico. De acordo com Vieira, Garcia e Maciel (2020) ${ }^{8}$, ao ficarem mais em casa devido à pandemia, as mulheres são vigiadas com maior frequência e restringidas de se comunicarem com familiares e amigos, o que amplia a margem de ação para a manipulação pelos companheiros, sendo esta uma forma de violência psicológica, a qual também se intensificou nesse contexto.

Outros agentes importantes de apoio às mulheres são os profissionais de saúde, seja em atuação na orientação preventiva, seja na prestação de assistência médica ou notificação de violência constatada durante um atendimento de caráter compulsório por observância à lei № 13.931, de 10 de Dezembro de 2019. . As palestrantes das áreas da psicologia e psiquiatria destacaram a importância dos serviços de saúde como intermediários entre vítima e órgãos judiciais em situações de violência, visto que muitas das mulheres com 
efeitos de agressões buscam, em um primeiro momento, o atendimento médico.

Durante o evento, que contou com participação considerável de estudantes da área da saúde, o papel desses profissionais diante da violência foi amplamente discutido, cabendo a eles não somente se atentarem às possíveis lesões físicas, mas investigarem sua origem e orientarem a paciente sobre como realizar encaminhamentos à esfera jurídica. Atestando a aplicabilidade desses conhecimentos no cotidiano dos serviços de saúde, tem-se o estudo realizado no Rio Grande do Sul ${ }^{10}$, no qual foram analisadas 20.999 notificações de violência contra mulheres do período de 2010 ao primeiro semestre de 2014. Tais registros foram efetuados por profissionais da saúde que atuam em hospitais, pronto-atendimentos e Unidades Básicas de Saúde do estado a respeito de casos de suspeita ou confirmação de violência, sendo que mais de $50 \%$ dos encaminhamentos de pacientes foram feitos diretamente a delegacias, incluindo unidades especializadas ao atendimento à mulher.

Mediante a análise das interações dos participantes ao longo do evento, pôde-se inferir que os espectadores tiveram seus conhecimentos sobre o tema aprofundados após as discussões promovidas, bem como avaliar o reduzido domínio prévio a respeito da postura dos profissionais de saúde diante das vítimas da violência contra a mulher. Tais interações se deram por meio de comentários feitos ao longo das palestras e, especialmente, durante as mesas redondas, as quais suscitaram maior aproximação entre as palestrantes e o público pelo envio de perguntas a serem respondidas ao vivo. Em adição, os participantes relataram ter suas dúvidas esclarecidas sobre canais de denúncia, bem como terem recebido incentivo quanto à prestação de queixas e à importância do acompanhamento psicológico nesses casos.

Considerando as limitações advindas do momento de pandemia global, a ação precisou se adequar ao ambiente remoto, o que não comprometeu a qualidade das informações oferecidas e, inclusive, facilitou uma maior abrangência de público em nível nacional. Em futuros eventos, a oferta de um serviço de atendimento gratuito de psicólogas para mulheres vítimas de violência seria uma forma de complementar a iniciativa de conscientizar as mulheres, levando a ação para o campo prático de intervenções na comunidade.

\section{CONCLUSÃO}

A partir da atividade, foi possível atestar que o tema da violência contra a mulher é cada vez mais imperativo, considerando o fato de, devido à pandemia, muitas mulheres ficaram ainda mais expostas a situações de violência ao estarem confinadas dentro de casa com seus agressores e impossibilitadas de pedirem ajuda. O presente artigo cumpre com o objetivo de relatar a experiência que discutiu a problemática e 0 acolher das mulheres, conscientizando e alertando os espectadores acerca dessa temática ao instruí-los sobre o procedimento em casos de violência, agregando conhecimento e enriquecendo a formação profissional e acadêmica dos participantes. Além disso, compreendeu-se a importância do trabalho em equipe multiprofissional para se obter um olhar transversal acerca da violência contra a população feminina. Outro ponto relevante foi a modalidade remota e gratuita do evento permitir a participação de um público expressivo e de diferentes regiões do Brasil, evidenciando que os eventos podem continuar tendo qualidade mesmo à distância. Vale destacar as limitações da atividade, sendo elas a má compreensão de alguns inscritos quanto ao fuso horário de realização do evento, bem como a dificuldade da comissão organizadora em ter o controle exato dos espectadores presentes ao vivo. Considerando a relevância do tema abordado, é importante que sejam desenvolvidas outras atividades de caráter semelhante em momentos futuros, com posterior desenvolvimento de pesquisas para a compreensão da violência contra a mulher no contexto local a fim de que intervenções sejam feitas de forma mais direcionada.

\section{CONFLITO DE INTERESSE}

Os autores afirmaram não ter havido conflitos de interesse na realização da pesquisa.

\section{FINANCIAMENTO}

Os autores declaram que não houve fontes de financiamento.

\section{REFERÊNCIAS}

1. Carvalho JBL, Pereira GHD et al. Maria da Penha e Lei do Feminicídio como mecanismos de combate a violência contra a mulher. Jus. 2020.

2. IPEA. Edição Atlas da Violência de 2019[Internet]. Disponível em: http://www.ipea.gov.br/portal/images/stories/PDFs/relatorio _institucional/190605_atlas_da_violencia_2019.pdf.

3. Gragnani J. 11 motivos que levam as mulheres a deixar de denunciar casos de assédio e violência sexual. BBC Brasil, Londres, p. 1, 13 out. 2017. Disponível em: https://www.bbc.com/portuguese/brasil-41617235 .

4. Portal PEBMED [ Internet ]. "Violência contra a mulher cresce durante a pandemia de 2020". Disponível em: https://pebmed.com.br/violencia-contra-a-mulher-crescedurante-pandemia-de-covid-19.

5. Fórum Brasileiro de Segurança Pública [ Internet ]. Atlas da Violência de 2020.. Disponível em: https://forumseguranca.org.br/atlas-da-violencia/.

6. BRASIL. Ministério da Mulher, da Família e dos Direitos Humanos. Coronavírus: sobe o número de ligações para canal de denúncia de violência doméstica na quarentena. 2020. Disponível em: <https://www.gov.br/mdh/ptbr/assuntos/noticias/todas-as-noticias/2020-

2/marco/coronavirus-sobe-o-numero-de-ligacoes-paracanal-de-denuncia-de-violencia-domestica-na-quarentena.> 
7. Roussef, Dilma; Gomes, Nilma Lino; Menicucci, Eleonora. Diretrizes para investigar, processar e julgar com perspectiva de gênero as mortes violentas de mulheres. 2016. Disponível em: https://www.onumulheres.org.br/wpcontent/uploads/2016/04/diretrizes_feminicidio_FINAL.p df

8. Vieira PR, Garcia LP, Maciel Ethel Leonor Noia. Isolamento social e o aumento da violência doméstica: o que isso nos revela?. Rev. bras. epidemiol. [Internet]. 2020 [cited 2021 May 18] ; 23: e200033. Disponível em:

http://www.scielo.br/scielo.php?script=sci_arttext\&pid=S 1415-790X2020000100201\&lng=en.

9. Brasil. Lei no 13.931, de 10 de dezembro de 2019. Secretaria Geral da Presidência da República. Diário Oficial da União 11 dez 2019.

10. Lawrenz P, Macedo DM, Hohendorff Jv, Freitas CPPd, Foschiera LN, Habigzang LF. "Violence against Women: Notifications of Health Professionals in Rio Grande do Sul”. Psicologia: Teoria e Pesquisa, 2018; 34: e34428. DOl.org (Crossref), doi:10.1590/0102.3772e34428. 